\title{
Construction of Waste Plastic Roads Using Black Viscous Blend of Hydrocarbons
}

\author{
Asmaa Abdulmajeed Mamhusseini ${ }^{1}$ \\ ${ }^{1}$ Civil Engineering Department, Faculty of Engineering, Tishk International University, Erbil, Iraq \\ Correspondence: Asmaa.abdulmajeed Mamhusseini, Tishk International University, Erbil, Iraq. \\ Email: asmaa.abdulmajeed@tiu.edu.iq
}

Doi: 10.23918/eajse.v6i1p121

\begin{abstract}
This research article deals with plastic solid waste management and damage to roads caused by massive traffic and pivot weight applied over roads in modern cities. A novel method is proposed for the construction of roads based on waste plastics major cities produced every day. The proposed system focus on the colossal waste of Polypropylene and High-Density Polyethylene in straight AC- 20 sectors at a verity of plastics formations. The plastics of waste were destroyed and blended with the hydrocarbons, with a grind mixer at a $160^{\circ} \mathrm{C}-170^{\circ} \mathrm{C}$ of temperature. Spectroscopy FTIR has additionally been utilized to consider the compound functionalities there in the hydrocarbons amalgamated. Unmodified hydrocarbons properties have been seen as improved with the progressions recorded in the characteristics of the Polymer Adjusted hydrocarbons (PAH). The PAH was seen with the purpose of the polymer of polypropylene, demonstrated significant impact happening above homogeneity in addition to similarity along with small straight augmentation within thickness, mellowing as well as infiltration esteems because of moderately massive changes intended to HDPE adjusted hydrocarbons. The thickness of non-modified hydrocarbons has upgraded along with the totalling of the thyrotrophic as well as polymers impact was examined. Most high-quality and contrary mixes for HDPE were independently shown the $2 \%$, and $3 \%$ contained polymer. The high improved, homogenous mix is accomplished along with PP at 3\% contained polymer. Three conspicuous pinnacles were recognized in the range of the non-altered hydrocarbons, happening pointed the $3050-2904 \mathrm{~cm}^{-1}$ range of IR repetition, typical of aliphatic asymmetrical and symmetrical extends in Chennai. $\mathrm{CH} 3$ and $\mathrm{CH} 2$ twists were likewise at the trademark frequencies of $1375 \mathrm{~cm}^{-1}$ and $1465 \mathrm{~cm}^{-1}$ separately. The least impact benchmark was seen inside the $2400 \mathrm{~cm}^{-1}-2100 \mathrm{~cm}^{-}$ ${ }^{1}$ territory, demonstrating the proximity of a weak - $\mathrm{C} \equiv \mathrm{N}$ or $-\mathrm{C} \equiv \mathrm{C}$ - bunch along with an absorbance 0.12 exactly. Usage of waste item plastics in folio alter conveys the positive aspect of a modest and robust method for improving ordinary hydrocarbons cover execution qualities and is an elective method to use the waste of plastics.
\end{abstract}

\section{Introduction}

Major cities that aim to maintain the green environment plan to utilize the advancement of natural production and manageability. On the other hand, for well over ten years which has seen the change of the goal into Supportable Improvement Objectives (SIOs), the nation is as yet thinking about the best possible removal and the executives of its City Solid Waste (CSW), particularly waste of plastic. Current waste removal techniques utilized are filling with land, cremation, and indiscriminate littering in the urban areas, districts and the open country. These removal strategies negatively affect human health conditions and the natural earth which leads to streams, canals, and side of the road, are stifled and loaded up with plastics wastes.

Most of the water bottling, soda, and soft drinks packaging materials are having high-density Polyethylene (HDPE) and Polyethylene Terephthalate (PET), where one of the most noticeably polluting material is polyethylene baggage. Consistently, a large number of things are either halfway otherwise totally plastics that are filling the land and spoil the land. Contingent upon the nature of the plastic, it might take any place from a couple of days to quite a long year to degrade. However, it never 
separates into particles that can be utilized in the environment. All things considered, plastic is one of the most noticeably awful reprobates with regards to (Programme, 2009), pollution of the atmosphere. The amount of traffic is growing and it denoted relating enlargement in the heavy pressure bearing breaking points of the road with its organization existence run. This problem has shown changes in the direction of improving the display of altered hydrocarbons blended used within the surfacing track of road surface, along with different types of added substances or modifiers to altered hydrocarbons, for instance, piece elastic, elastic latex and polymers, so forward. Two primary methods accomplish adjustment; Dry procedure includes the direct fuse of plastic waste, those are mixed with hydrocarbons, to set up a moderate plastic hydrocarbons solid blend and the Wet procedure which includes, concurrent mixing of hydrocarbons and plastic waste. The utilization of polymer altered hydrocarbons to accomplish better black-top asphalt finishing has been studied in the papers (King \& King, 1986; Isacsson \& Lu, 1995; Zorrob \& Suparama, 1995) which revealed the utilization of reused plastics made overwhelmingly out of polypropylene and less density thickness polyethylene in plain hydrocarbons solid blends with expanded toughness and improved life. Protection from distortion of asphaltic cement adjusted with less density polythene has enhanced in investigation with unaltered blends. The need of this study is to produce logical information that will figure the reason for utilizing plastic adjusted hydrocarbons in the construction and revamp of the road in major cities, just as give logical information on the elective reusing choices for plastic waste.

\section{Equipment and Technologies}

\subsection{Equipment}

\subsubsection{Altered Hydrocarbons (Bitumen)}

A black viscous mixture of hydrocarbons is called Bitumen. It is always used in the grade level of AC20, which was acquired from a restricted road contract worker in Erbil. The properties of Altered Hydrocarbons have been demonstrated in Table 1. After the trial methods, the altered properties were contrasted with the Highway Department (HD).

Table 1: Property of Altered Hydrocarbons

\begin{tabular}{|l|l|}
\hline Infiltration $(\mathrm{dmm})$ at $26^{\circ} \mathrm{C}, 150 \mathrm{~g}, 6 \mathrm{~s}$ & - \\
\hline Soften Dot in Degree Celsius & $50-58$ \\
\hline $\mathrm{KV}$ at $149^{\circ} \mathrm{C}$ & 350 \\
\hline $65^{\circ} \mathrm{C}$ for Viscosity & $2050+$ or - and 450 \\
\hline Gravity specification & $1.05-1.16$ \\
\hline
\end{tabular}

\subsubsection{Plastic}

Plastic water bottles, rubbers, bags, and covers were collected from various public places and various residential in significant cities. 


\subsection{Technologies}

\subsubsection{Altered Hydrocarbons}

The try procedure has been utilized; samples were readied, utilizing a melt mixing strategy. Hydrocarbons were taken 400 grams which have been warmed in a stove till liquid situation, as well as polymer, has been gradually encompassed. Rotation for blender has been kept over $125 \mathrm{rpm}$ along with high temperature, somewhere in the range of $165^{\circ} \mathrm{C}$ and $175^{\circ} \mathrm{C}$ of heat. The convergence of HDPE and PP ran from $0.10 \%$ to $-5 \%$ with the weight of mix with an augmentation of 0.6 percentages. Blending was proceeded for $35 \mathrm{mins}-0.5 \mathrm{hr}$ to deliver homogenous blends. The Polymer Altered Hydrocarbons (PAH) was then fixed in compartments and put away for additional validations. Experimental tests, for example, penetration, mellowing point, and thickness were then directed on the readied tests.

\subsection{Laboratory Empirical}

\subsubsection{ASTM D- 5}

Analis Penetrometer P734 has had a test with the regular $105 \mathrm{~g}, 30^{\circ} \mathrm{C}, 7$ seconds penetration, on-base PMB, and Altered hydrocarbons with the grouping of polymer changing between $0.6 \%$ to $4 \%$ of the weight of the Altered hydrocarbons. The outcomes of that test have been represented in Figure 1.

\subsubsection{ASTM D- 36}

The standard test of Ring and Ball examines to decide the consistency of the altered hydrocarbons. It is demonstrating the temperature at which a difference in stage from healthy to fluid happens. The standard steel ball which 3/8-inch size and $3.55 \mathrm{~g}$ weighting, come down and contact 2.5 millimeters away from the base plate. The results of these experiments have been demonstrated in the following graph (Figure 2).

\subsubsection{ASTM D- 4402}

This experiment was done on the non-alternated polymers and altered hydrocarbons with the help of the DV- III Ultra Programmable Brookfield viscometer. The measurements of kinematic viscosity were at 65 degrees and 140-degree heat correspondingly. It was taken on all types of polymers with an above concentration of $4 \%$. These experiments outcomes are represented in Figure 3(a) and Figure $3(b)$.

\subsubsection{FTIR}

The Fourier transform infrared spectroscopy validation has been performed based on the Altered Hydrocarbons and Altered Hydrocarbons Plastic Composite (AHPC) to decide whether an acid change happened during the scattering of the waste plastics inside the black-top mixer. The Interspec 200- X Fourier Transform Infrared Spectrometer was used for this test measuring purpose. Every spectrum has been taken 34 times per minute for scanning frequency purposes. 


\section{Results and Discussion}

\subsection{Penetration}

Figure 1 demonstrates the results of non-altered hydrocarbons (bitumen), HDPE Altered Hydrocarbons and PP, the penetration measure $105.4 \mathrm{dmm}$ was degreased for standard hydrocarbons to $89.04 \mathrm{dmm}$ for HDPE and 0.6 percentage absorption of polymers clearly shown the PMB hardness has been increased. The reason is the utilization of the HDPE and high atomic weight polymer. Based on (Yousefi A.A, Kadi A. AIT, 2000), the dissolving temperature of PP and HDPE is $168^{\circ} \mathrm{C}$ and $138^{\circ} \mathrm{C}$ separately, at the temperature of Polyethylene up to $165^{\circ} \mathrm{C}$ is in liquefy stage; that retain various oil and discharge low sub-atomic weight portion into the Altered Hydrocarbons which expands the PMB thickness.

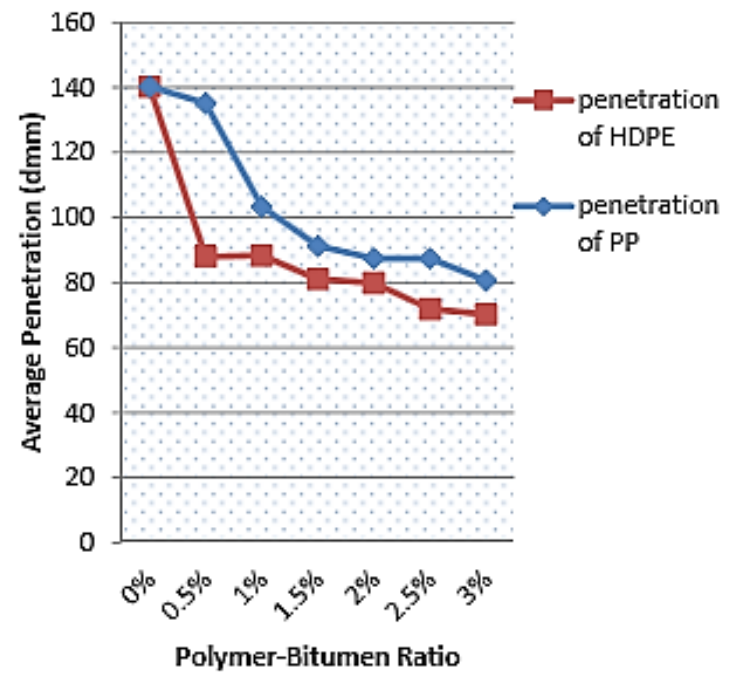

Figure 1: Result of Non-Altered Hydrocarbons (Bitumen)

Therefore, it expands the consistency before the finish of the blending process, and when it cools, solidify blend was framed. The solidifying of the Altered Hydrocarbons can be gainful as it builds the solidness of the resource (C.D, 2003); in this manner, the heap dissemination capacities of the construction yet additionally can prompt fussing or splitting. Infiltration is identified with consistency and exact connections have been produced for Newtonian resources. On the other hand, the entrance is estimated over a scope of temperatures; this is the dimness of the perfect Altered Hydrocarbons which can be set up.

\subsection{Softening Point}

Figure 2 has been demonstrated the increase of sequence of a line of PMBs HDPE soften temperature above observation of $4 \%$ for polymer incomparably slandered penetration. The alteration of Thermoplastic (Yousefi \& Kadi, 2000) does not essentially influence the conditioning point when contrasted with the entrance. This is owing to the interior structure framed by the polymer; it is by all accounts thermodynamically steady and does not fundamentally influence the conditioning purpose. The HDPE represented a fast improvement of softening dots into PP comparison (Noor et al., 2011). This affirms the PMBs with an expansion soften dots have been found and upgraded in asphalt execution qualities regarding rutting, weakness and temperature vulnerability. Once more, like PMB, $\mathrm{PP}$ is giving lesser variety during relaxing happened, which is due to homogeneity accomplished while 
mixing of PP along with base Altered hydrocarbons. The main reasons for this is; it is less atomic weight and has progressively polar aspects. In this manner, PP along PMB possibly has been provided better rutting obstruction at colossal temperature.

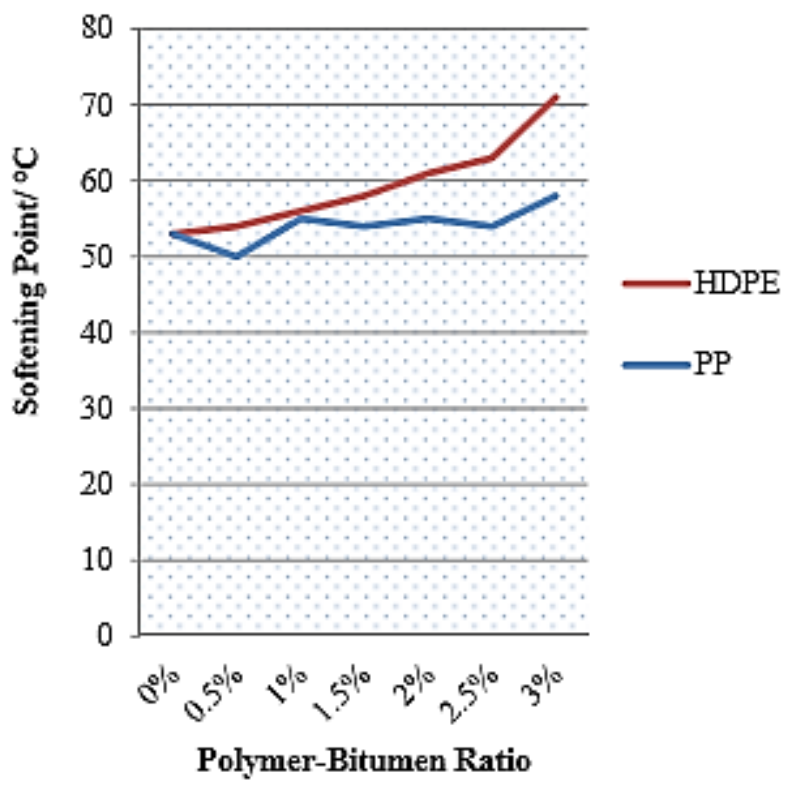

Figure 2: Linear Improvement of PMBs HDPE Soften Temperature

\subsection{Viscosity}

When with polymer and Altered Hydrocarbons is mixed, a single multi-stage framework is developed. It is a stage which has massive molecular substances that don't consume for the polymer consistency achieved by the arrangement for progressively complicated interior domain (Hadidy \& Qui Tan, 2009; Stastna, Zanzotto, \& Vacin, 2002). Stream conduct of an Altered Hydrocarbons resource depicted as far as consistency, displays Newtonian as well as non-Newtonian qualities relying upon procedure and source of unrefined. In the inner structure of the base Altered Hydrocarbons additionally assumes a critical transition. Figure 3 has been showing the results of standard Bitumen with a consistency of $365 \mathrm{CSt}$ at $137^{\circ} \mathrm{C}$ presentation increment in thickness with the expansion in polymer focus and shear tempo. On the other hand, Non-Newtonian conduct is seen with the diminishing in thickness as shear tempo increments for the two polymers at $2.6 \%$ focus. The non-Newtonian marvel has subject to the SR rate along with possibly affected for PMB (D., 1997) for the interior structure. The variance of consistency observed was more to 2.6 percentages for HDPE convergence of polymer. The blended conduct in with the decline in thickness as shear rate increments and increment again inconsistency is an after-effect of thyrotrophic impact. 


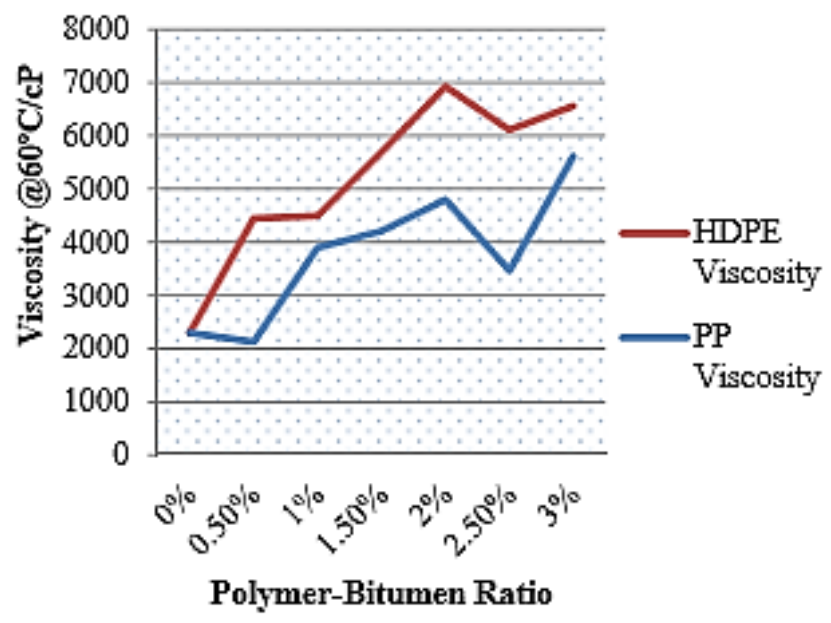

Figure 3: Difference of Blended Represented of HDPE and PP

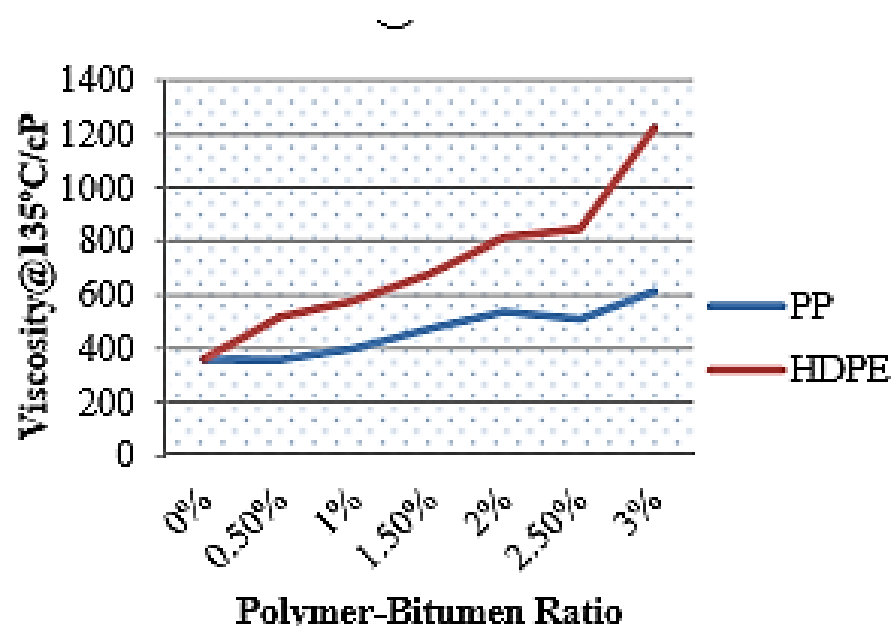

Figure 4: Difference of Ratio of HDPE and PP

The thixotropic direct of balanced bitumen may be a result of the recoverable breakdown with domain were to be generally brought in the multi-phase course of action for polymer changed alter carbonate (Noor et al., 2011). Furthermore, the plastic direct of PMB will have to be credited towards the breakdown of the domain, otherwise existing polymer stuff in a balanced situation, going to progressively balanced. That instance provides to low guaranty from stream anyway with extension in SR rate; that instance provides to high hindrance because of agglomeration, combination otherwise flocculation of stuff in various phase structure while entombing molecule powers as Brownian, Vander Dividers powers happen to categorical. HDPE is not totally dispersed in bitumen considering the higher nuclear weight and in that limit show both viscoelasticity and thixotropy at all centralizations of polymer in the blend (Sybilski, 1997). The PP offers less change as can be looked for all groupings of the polymer in the diverse blends given in Figure 3.

\subsection{Experiments of Fourier Transform Infra-Red}

The high thickness polyethylene is fundamentally aliphatic, made out of just base hydrocarbons, and it is altered. Range of uncovers that $0.6 \%$ of HDPE adjustment of the total cover yields over $25 \%$ improvement in the aliphatic gathering power in the mixer, in the non-altered fastener moderated from 
1.5 to 1.29 . The $\mathrm{CH} 3$ and $\mathrm{CH} 2$ rotations by the side of $1376 \mathrm{~cm}-1$ and $1466 \mathrm{~cm}-1$ are additionally seen to increment in power. The augmentation of fourfold can likewise be seen in the powerless $\mathrm{C} \equiv \mathrm{N}$ or $-\mathrm{C} \equiv \mathrm{C}$ - gathering as its occurrence becomes 0.6 indisputably. Spectra for 1.5 percentage HDPE and 2.5 percentage HDPE individually show significant powers in the tops for aliphatic $-\mathrm{C}$ $\mathrm{H}$ gatherings, the $\mathrm{CH} 3$ and $\mathrm{CH} 2$ rotations, just as the triple bond $-\mathrm{C} \equiv \mathrm{N}$ or $-\mathrm{C} \equiv \mathrm{C}-$ gathering. This recommends a functioning attachment among the polymer strands and the Altered Hydrocarbons parts. Initially, no new particular useful findings are framed; it tends to be additionally concluded that the improved forces within pinnacles towards the consequence of fruitful mixing towards polymer keen on folio grid. In any case, in spectra used 2.6\% HDPE, HDPE as well as 1.6\% altered hydrocarbons; it tends to be seen that the powers of three noticeable pinnacles are just improved marginally when contrasted with those displayed by the spectra for $2 \%$ and $1 \%$ HDPE changed hydrocarbons. Since the range of $4 \%$ HDPE plastic altered hydrocarbons, it tends to be observed that it should be in less impact for the plastic structure happening practical blending of hydrocarbons. This perception clarifies the vulnerability of this polymer- hydrocarbons blends to experience net phase- division under undisturbed circumstances. Four percentages of polymers tacking for the HDPE is seen to have the least extraordinary pinnacle. This proposes a poor collaboration between the plastic and the hydrocarbons at that level of mixing. The observed of Polypropylene plastics to affect the microstructure of the folio at low polymer proportions when match with HDPE. There is no augmentation in the power of the noticeable tops as polymer proportion is expanded from $0.6 \%$ to $1.6 \%$.

Somewhere in the range of 3\% and 4\% PP adjustment, the force of the assemblies retaining in the aliphatic area become increasingly articulated. This is characteristic of the utilitarian impact the polymer starts to show as its rate proportion increments. The generally extraordinary top for PP likewise happens somewhere in the range for PP content of $2850 \mathrm{~cm}^{-1}$ and 3000 at $3 \%$. The relating pattern of increment in maximum power as polymer proportion increments of the diverse spectra recommends the polymer proportion could have been expanded past $4 \%$ for adjusted hydrocarbons of PP.

\section{Conclusion}

The expansion modifiers of thermoplastic towards traditional altered hydrocarbons are well recognized to get better the viscous materials conduct of Altered hydrocarbons. There are a couple of materials to be utilized, Polypropylene (PP) and high thickness polyethylene (HDPE) which were seen to show specific measures of impact. The spectroscopic examination via FTIR spectrophotometer did not support new methodologies particularly from the range of the base fastener for all the Altered hydrocarbons tests. On the other hand, the first noticeable pinnacles happening at the $-2850 \mathrm{~cm}^{-1}$ and $3000 \mathrm{~cm}$ minus 1 for aliphatic C- $\mathrm{H}$ extending, $2500 \mathrm{~cm}$ minus $1-2150 \mathrm{~cm}$ minus 1 for connection of triple - $\mathrm{C} \equiv \mathrm{N}$ or $\mathrm{C} \equiv \mathrm{C}$ - gathering and $1486 \mathrm{~cm}^{-1}, 1546 \mathrm{~cm}^{-1}$ for $\mathrm{CH} 3$ and $\mathrm{CH} 2$ rotations are seen to increment in power contingent upon the polymer category along with mixing proportion. This recommends efficiently blended for polymer characterize into the altered hydrocarbons framework. It has better outcomes acquired inside restrictions of investigation, for constant PMB reasonable towards road paving with Polypropylene. The experimental evaluation demonstrated that waste form of plastic altered hydrocarbons conveys extraordinary guarantee as an elective reusing technique for plastic waste administration in major cities, just as a non- traditional, altered fastener for road pavement. Further examinations need to be performed to explore the execution of field test surface along with 
PMB in order to assess the impact on capacity, immersing, splitting opposition beneath different traffic circumstances.

\section{References}

Bhattacharya, S. (1997). Rheology fundamentals and measurement. Royal Melbourne Institute of Technology. Australia.

Hadidy, A., \& Qui Tan, Y. (2009). Effect of Polyethylene on life of flexible pavements.

Construction and Building Materials, 23, 1456-1466.

Isacsson, U., \& Lu, X. (1995). Testing and appraisal of polymer modified road bitumen-state of the art. Material structure, 28, 139-159.

King, G. N., \& King, H.W. (1986). Polymer modified asphalts, an overview. American Society of Civil Engineering, 240- 254.

Noor, Z., Kamaruddin, I., Madzalan, N., Isa, M. (2011). Rheological properties of polyethylene and polypropylene modified bitumen. International Journal of Civil and Environmental Engineering, 4(12), 381-385.

Programme, U. N. (2009). Converting waste Plastics into A resource: Assessment guidelines.

Stastna, J., Zanzotto, L., \& Vacin, O. (2002). Viscosity functions in polymer-modified asphalts. Journal of Colloid and Interface Science, 259, 200-209.

Sybilski, D. (1997). New simplified equation for the computation of absolute viscosity of polymerbitumens. Materials and Structure, 30, 182-187.

Yousefi, A.A., \& Kadi, A. A. (2000). Composite asphalt binders: Effects of modified RPE on asphalt. Journal of Materials in Civil Engineering, 113-123.

Zorrob, S.E., \& Suparama, L. B. (1995). Laboratory Design and Investigation of Proportion of bituminous Composite Containing Waste Recycled Plastics Aggregate Replacement (Plastiphalt). CIB Symposium on construction and Environment Theory into Practice. 